\title{
You can't do it on your own: \\ Gardening as an analogy for personal learning from a collaborative action research group.
}

\author{
Marian Woolhouse \\ School of Education \\ University of Hertfordshire \\ de Havilland Campus \\ Hatfield \\ AL10 9AB
}

\begin{abstract}
This article explores the factors which contributed to personal learning and development as a result of being a member of a collaborative action research project group. The project took place in a University School of Education and involved five lecturers and the students they were supervising for their dissertations. Data were collected by interviews with lecturers and students, regular meetings and other activities, all of which were facilitated by a research assistant. Gardening is used as an analogy to action research with similarities between the two activities being made. Two interlinked factors are identified as being crucial for the learning which took place - time (in terms of making time for the research and realising that development is not always instant) and support from others (both within the action research group and the wider research community). These factors, together with some lessons drawn from this collaboration, (which may be useful for others engaging in this type of activity) have led to the realisation that "you can't do it on your own”.
\end{abstract}

\section{Introduction}

What makes me stay at the computer now when I would like to get out into the garden and dig over a patch of soil which will be soft after last night's rain? It has something to do with being involved in a collaborative project with a group of colleagues whom I did not want to let down. 
This project involved five university lecturers learning about and developing their practice as supervisors of students preparing dissertations. It was part of a larger project designed to improve teaching and learning on the department's in-service continuing professional development programme for school teachers and college lecturers. The ‘dissertation supervision group’ emerged from an invitation to all colleagues involved in this work, to participate in a project to investigate their practice. The overall project leader also 'led' this small group. The key features, of the small group, were the opportunities for each supervisor to reflect on her practice through a series of interviews, group discussions, information on the student perspective and the opportunity to observe each other's tutorials, experiment with new ideas and evaluate their effectiveness. All these elements provided data for us to consider in relation to our supervision of dissertation students. We wrote about our experiences of supervising in a variety of ways, including a story about some aspect of our supervision experience (Burchell \& Dyson, 2000).

In addition, we had regular meetings in which our discussions and reflections were wideranging in nature and scope. Notes of the meetings were taken and formed another source of feedback for each supervisor. The research element of the project benefited from the availability of a 'research assistant' which may be seen as a departure from traditional action research with involves only the participants. Her role, although different from the five lecturers who were investigating their practice, was not a 'subservient' one as she participated in all aspects of the research including conducting the interviews, helping to organise the project and contributing her own perceptions of the project's outcomes and 
processes. Her role could be better described as a 'colleague researcher' and this term will be used throughout this article.

In this article I will present my personal responses and learning from engaging in this year long project. The individual perspective of a collaborative project is not often heard as results of joint work are usually disseminated, by the group, and represent the results of the project rather than an individual's voice. There has been no group publication of this research as the outcomes were individual for each of us. I was originally motivated to join the group to help investigate the process of dissertation supervision and develop my skills in this area of my work. The project prompted me to ask a number of key questions. How do I begin to question my working practices when I feel that I have a well worked out supervision style which is tried, tested and seems to work? What kind of supervisor am I? How do I develop my practice when I see myself as already skilled and organised? I invite readers to substitute their own version of these questions depending on their own professional background and context - how do I develop as a teacher, social worker, nurse, doctor, educational administrator, police officer?

I knew that without the framework of a group to work within, I would not 'find the time', in a busy professional life, to engage in reflection and research. Increasing workloads have made many teachers (and other professionals) feel isolated and this in turn can lead to introspection (Golby \& Appleby, 1995). Undertaking the writing of a dissertation can also be an isolated occupation, as is supervising a student in a one-to-one relationship. Membership of a group project offered me a chance to look beyond the isolated 
relationship of student and supervisor with a group of colleagues engaged in a similar process.

After discussing some features of collaborative action research related to my experience of this project, I will explore the two key aspects which were crucial for developing my knowledge and understanding of supervising dissertation students, and the process of collaborative action research. These are firstly time, and secondly support from others. The support I received is considered both in terms of personal support from colleagues also involved in the research project, and from the wider educational community whose members have written about their experiences. Finally, I will share some of the lessons I learnt from this group about collaborative action research and illustrate how, as a keen gardener, I came to see the analogies between action research and gardening and consequently gained a greater understanding of the action research process itself.

\section{Collaborative Action Research}

When students ask me "What is Action Research?”, my answer goes something like this: 'you research some aspect of your own practice with the results of data analysis informing that practice to help you develop and improve it'. As a classroom teacher the action research should also impact upon (improve) learning in the classroom. It could be argued that all good teachers engage in action research, often without thinking in any depth, by reflecting on their practice in action (Schön, 1983) to improve learning in their classrooms. This process can be enhanced by making the time for some form of planned data collection and analysis, as was the case in our project. However, action research is 
much more complex than this suggests and takes many different forms which is the "right and proper consequence of action research being grounded in the values of the individuals or group who are carrying it out.” (Somekh, 1995, p340) What became apparent, through our data gathering and discussions was that although we had different approaches and ways of working with dissertation students we shared common values about what we were doing and why and a commitment to improving our practice. Our expectation was that we could do this by making the time to be part of the group and supporting and challenging each other.

For many practitioners action research offers a practical way to research and develop practice and in recent years it has grown in popularity, in part because it is the process of attempting to have new thoughts about familiar experiences, and about the relationship between particular experiences and general ideas (Winter in ZuberSkerrit, 1996, p14)

For both experienced and inexperienced researchers the familiar is more comfortable as a starting point than the unfamiliar. As the results of action research feed "directly into practice with the aim of bringing about change” (Somekh, 1995, p341) it can facilitate “actual improvements in practice”. (ibid, p340) This can further motivate practitioners to continue their engagement in systematic action research. However, working alone, whilst it does not involve the time commitment of working within a group, can be isolating. For some this can be de-motivating, which means practitioner research is often not continued even if there is an improvement in practice. Working within a group can boost motivation and mean research, and improvements, continue. 
Different action researchers describe the process in different ways. For example, Kemmis (in Reason and Bradbury, 2001) offers the distinction between technical, practical and critical, or emancipatory, action research. The technical form is "oriented essentially towards functional improvement measured in terms of its success in changing particular outcomes of practice". (ibid, p92) Practical action research, "also aims to inform the ... practical decision-making of practitioners" (ibid) and aims to give them an understanding of "themselves as subjects of a practice" (ibid). Critical, or emancipatory action research aims, in addition, to assist "practitioners to arrive at a critique of their social or educational work and work settings”. (ibid) Only by being involved in this collaborative project did engage with literature of the wider academic community which helped me understand both the theory and practice of different forms of action research. My practice of supervising dissertation students improved through my greater understand of action research by being involved in it myself.

The project being discussed here did bring "about improvements in practice” (Somekh, 1995, p341) so achieved Kemmis' technical definition of action research. It also addressed the practical and critical aspects in that, for me, I came to better understand myself as a practitioner and both a 'subject' of action research and a researcher, with a greater critical awareness of the educational work setting. The term 'subject' implies the research is being done to or on that person and as action research is about practitioners investigating there own practice, there appears to be a contradiction here. By working collaboratively, with an assistance of a colleague researcher, we extended the definition of action research and moved between the roles of researcher and researched. 
A very interesting development in action research, and one which is appropriate to the project being discussed here, is what Kemmis and Wilkinson (1998) term 'participatory action research (PAR)'. They borrow from Fals Borda (1979) to say that it "aims to help people investigate reality in order to change it” (Kemmis and Wilkinson, 1998, p21) and add themselves that it "helps people change reality in order to investigate it" (ibid). This is done by investigating what they do in reality, and then changing that reality to constitute new realities. They extend the steps usually associated with action research and say that PAR is "best undertaken collaboratively by co-participants in the action research process” (ibid, p22). PAR is a collaborative social process of learning. This has a resonance for me. I became involved in the project to investigate myself as a supervisor and develop my practice, but being part of a group was a greater motivator, because I hoped to learn from others to further develop my understanding of the supervision process. We started by wanting to investigate what we did (our reality) in order to develop (change) it, or receive reassurance about our practice. In the process we changed our reality (what we did) so we could investigate it. Instead of being isolated we worked together - we met regularly, we discussed our own and others’ practice and perceptions, we observed each other's tutorials. We contributed to the research design by being involved in the development of interview schedules and were the 'subjects' of that research as we were interviewed by the researcher colleague. Some of the challenges entailed by this 'change' are discussed later in the paper. 
Action research is often seen as a series of spirals or cycles, with stages or steps, whereby the results of analysing the data collected feed into the next step in researching practice, but the steps should be viewed as an "integrated process" (Somekh, 1995, p342).

Different researchers have described this process in slightly different ways. As early as 1946 Kurt Lewin presented a process which involved planning, acting, observing, and reflecting. In the next cycle the planning was a result of the analysis of the previous cycle (McNiff, 1988). This simple model of action research has been refined by other researchers / authors to emphasise, for example, the importance of continually moving forward or to give guidance on how the steps can be engaged in more effectively. Some expand the model to take into account that in reality life / research does not go "along one track at a time [to show how] related but similar problems will arise and oust the main focus” (McNiff, 1988, p28). Others, for example John Elliot and Dave Ebbutt, see this essentially sequential spiral model as too simple and have suggested more complex representational models. (McNiff, 1988).

Although our project was essentially a series of spirals or cycles, the various dimensions of the project - for example, our own interviews, the group meetings, the story writing all interacted with each other. Hence, our research project did not go "along one track at a time” (McNiff, 1988.p28) and as all the component parts of the project interacted, we found many similarities and differences in our individual perspectives and practices. The more complex models of action research, discussed above, better fitted what we did. 
The increased emphasis in many professions on their members undertaking self directed continuing professional development places the individual at the centre of their own learning. As professionals we have a responsibility to be continually questioning our practice and attempting to develop and improve, but doing this alone can be very isolating. Thus, collaborative action research is a way for a group of people to gain a greater understanding of a part of their work which they have in common. Collaborative action research is often used to reach a collective solution to a problem or a collective view about an issue. In our group there was no problem to solve or issue to have a collective view about. We were a group of colleagues wanting to gain a better understanding of one aspect of our work by sharing our experiences and learning from each other and from the students we were supervising. We collaborated to enhance our understanding of one aspect of our work, meaning

that everyone's point of view will be taken as a contribution to resources for understanding the situation, and no one's point of view will be taken as the final understanding of what all the other points of view mean ... it is the variety of differences between the viewpoints that makes them into a rich resource. (Winter in Zuber-Skerrit, 1996, p22)

Further discussion of collaboration is included in the following section.

\section{Key features for personal professional development through action research}

As I look back on my involvement in the project I can identify two key features which facilitated my professional learning in two inter-related fields: supervising dissertation students and more generally in improving my understanding of action research. These two elements (which are themselves inter-related) are: 
- time - putting time aside for action research and recognising that development is not always instant;

- support from others - the benefits (indeed for me the necessity) of having colleagues to work with who give encouragement to keep the process going. Support also includes that gained from reading about others' experiences, whether these are of the colleagues involved in the project or published work.

\section{Time}

When I review the transcript of my first interview where I was asked to describe myself as a supervisor, I see that I viewed myself as a supervisor who stressed the importance of practical aspects when supervising students. One of these aspects is time. I encourage students to devise timetables for their work and help them stick to deadlines. It is only natural, therefore, that 'time' should figure highly in my reflection on involvement with the action research project. The discipline of having time blocked out in my diary for regular meetings with colleagues and interviews was the only way that I could ensure that time was set aside for the research project.

Some people manage their time to allow them to engage in individual research, or study for a distance learning qualification. For example a friend of mine gained her Open University degree by studying from 5-7 o'clock every morning before getting her son ready for school and earning her living as a child minder. Others, (including myself) cannot maintain the focus if left alone, hence the importance for many of us to work collaboratively on research, or, in other circumstances, to attend a course of study rather than study on one's own. 
Personal time (and time for meeting with others) has to be managed. The practicalities of professional life - preparing for the next class, developing courses and responding to all the varied demands which come our way - intervene and the less pressing desire to engage in action research gets lost. One might expect that in a University Education Department this would not be the case, and, indeed, colleagues may have more time and opportunity to do this than most teachers in schools or colleges. However, "working conditions for teacher educators, as for teachers, are singularly unconducive to the systematic pursuit of research”, (Dadds, 2002, p11) and we are limited by being at "the centre of a demanding and involving job” (Lomax, 1991, p105) For all practitioners time for research is limited 'since the primary responsibilities of the action researcher are those of a working practitioner' (Somekh, 1995 p341) In addition teacher educators, including myself, have come into higher education from being teachers in schools and colleges where the culture is not always supportive of research. As Dadds (2002) reminds us "research is an attitude ... an approach of mind” (p14) and the type of research needs to accord with the researcher's attitude. This collaborative way of working, with an emphasis on developing practice, was a model which fitted with my professional and personal values of teaching and of research.

So how do you 'find' the time for engaging in action research at the same time as continuing in your job and responding to the demands on your time outside of work? This is about balancing demands and making choices. Throughout the project we needed to recognise the competing demands each of us had on our time, and to accept how this 
would affect the collaborative aspects of our enquiry, for example arranging group meetings within our busy daily routines. In balancing these demands each person finds the best solution for themselves. For me getting up early in the morning at weekends provides a quiet time for reflection and writing, leaving the rest of the day to do what you should do at weekends, including, for me, looking after and developing the garden.

With action research there is also the need for time in another sense - time to allow ideas and thoughts to emerge and mature. This is about giving yourself permission not to be 'active', but like the gardener to plant the seeds or cuttings and wait from them to grow. Sometimes you get a wonderful surprise like a yucca plant, which has been in the garden for 6 or 7 years, flowering and giving a spectacular display. Action research is, for me, like gardening - it’s not about anything instant. The current trend, in both research and gardening, is for instant solutions. 'Ground Force' brought instant gardening to our television screens in the UK and is now instantly gardening in the USA. But, seeds of ideas, like plants from seeds take time to establish and develop.

I am writing this in the third week in May during the Chelsea flower show. Many of the 'gardens' there cannot exist in reality as plants which flower in different seasons are shown together - some being forced to flower early, others held back - but they look good on the exhibition stand or in the show garden. Much current research is like this - it looks good but is not 'real' - it is done in response to an immediate 'problem' which needs ‘solving'. Real action research needs time and, like a garden, the best are those projects which have been developed with personal meaning and significance - the cutting 
or seedling given by a friend, or one found by chance, or a special plant tended with loving care. For me, probably the most important factor in successful gardening is the commitment involved in establishing good garden soil in which ideas, sorry, I mean plants, can grow. It is also important to make time to review / reflect on your efforts in the way the old gardener (interviewed by Geoff Hamilton for the 1996 Paradise Gardens series) said “sometimes I just sits and thinks, and sometimes I just sits”.

\section{$\underline{\text { Support from others }}$}

Just as some plants need support from other plants - both in the physical and aesthetic sense, so researchers need support from other researchers. Chivers (2000) observes that "it is strange that our concept of reflective practice is based on the lone individual when so much professional work and learning is carried out in teams and groups” (p2). The discussion and debate, listening to colleagues and having the opportunity for them to listen to us, are essential features of the process. In the same way as reading a good article can inspire thought and reflection in the reader and lead to questioning of one's own practice, so can open discussion and debate in a mutually supportive and collaborative atmosphere. It helps to "keep us going”. As Winter (1989) so aptly says "it is collaboration among the membership of a situation ... which keeps its processes going” (pp 55-56). It might be easier, in terms of time, to work alone, but it is a very special plant, indeed, which looks better on its own rather than in combination with others. Support comes not only from colleagues in the intellectual sense but from the framework in which the collaborative research takes place. Just as some plants need the support of a fence, pergola or trellis to flourish, so collaborative research needs a framework too. 
Griffiths and Tann, writing about reflective practice, suggest that critical reflection upon one’s own practice "needs to be facilitated by others" (Lomax, 1991, p104) and Lomax herself sees relationships with others as a key element in action research. At an Australian conference, Coles (1999) identifies "the collaborative support and interest of others” (p5) as a significant factor in bringing change in a participant action research approach. Kincheloe (2003) also describes how connecting with others who share a common interest, can be an empowering process likely to lead to changes in practice:

'When the teacher as researcher connects with other teachers as researchers and with faculty ... a dynamic process ensues. This is the basis of educational change, of critical pedagogy, of a democratic workplace.' (p39)

Whilst I would not claim that the changes which happened as a result of involvement in this project were as dramatic and far reaching as Kincheloe suggests, I have no doubt that the opportunity to work with others was a key factor in supporting my own professional development.

The individuals involved in this action research were a self selecting group, and although it was often difficult to find the time to meet, we valued the support we received from each other for our own development and learning. We saw a purpose in meeting with colleagues, some of whom we would not normally come into close contact with. Even though we had the same focus in our activity we had a variety of backgrounds and interests. We listened to each other, discussed and debated and valued everyone’s contribution and ideas. There was an equality in our involvement, despite the length of 
experience in supervising dissertation students which ranged from over 15 years to doing it for the first time and even though we had a 'leader' and the colleague researcher was involved. We established a "collective expectation" of how we worked together and a commitment to the group. This was done by accepting the value of what everyone had to offer and also the amount of time each could commit to the meetings and other activities. Our relationships with each other had developed beyond that of colleagues who were involved in the same activity.

The term 'critical friend' has been used by some to describe a relationship that goes beyond that of being colleagues, to people who could contribute new ideas, valuable resources, alternative strategies ... frequent positive feedback was reassuring and the gentle questioning of dubious practice offered a safe environment in which to discuss weaknesses. (Golby \& Appleby, 1995, p154).

Although the 'critical friend' relationship, as described by Golby and Appleby, may be too 'intense' to accurately describe our group there were elements of this in our interaction. Others can often see things in what you do, say or write which you may not yourself have seen as significant. By reflecting on what is reflected back to you it is possible to see more clearly and to move your own thinking forward. A 'critical friend' relationship is often one-to-one but by being part of a group the intensity of this is diffused.

Lomax (1991) says of her research that in "negotiating the meaning of events with others ... some sort of collaborative activity [is a] key role for the peer group acting as a critical support set” (ibid p106). She uses the term 'support set' to refer to people as 
...a group of critical friends who share my reflections. They are a sounding board for my proposed action: they listen. They help me evaluate: they question. They draw a line when the challenge becomes too great; they support. (Lomax, 1991, p106)

I believe that this definition is perhaps one of the most apt I have found to describe the relationships within the action research group being discussed here. For example my critical support set helped me to focus on the following:

- I had not realised how much I had emphasised the need for support from others to enable me to take part in the project. In discussing what we would focus on for one aspect of our writing, a colleague reflected back to me this focus and I came to realise how important this was to me.

- When writing our 'stories', (referred to earlier in the introduction) I had seen it as just that - a story of a "typical tutorial in the life of...”. Story telling as a way to reflect on practice can be enhanced when others read the story, and it could be argued that "to benefit fully from the story writing process ... the writer needs external comment from a reader who can contribute a different perspective on the issues” (Burchell \& Dyson, 2000, p446). When discussing my story with the research assistant I came to see the importance of another perspective. She suggested interpretations for aspects of my story which, when reflected back, enabled me to see beyond the surface of the 'story' to some of the underlying principles of my personal theories of supervision. This gave further insight into the whole process.

Support comes not only directly from one's own colleagues but indirectly. For example, being involved with others in a collaborative venture led to recommendations for books 
and articles to read and managing time to read them. Reflecting on what you have read can move on your own thinking and having an opportunity to discuss what you gained from it can move your thinking on further. Being asked to read and comment on what others in the group had written gives support and assistance in both directions. Their writing acted as a stimulus for my own thinking and reflection, and hopefully my comments helped move them on in theirs. We also write for ourselves as writing about one's own experiences and the processes through which one moves "involves clarifying and exploring ideas and interpretations” (Winter in Zuber-Skerritt, 1996, p26). Hopefully your writing will, in turn, help to move others on in their thinking and a continuous chain is forged which benefits the whole educational research community. Ryan (1997), discussing his development as a teacher educator through writing, expands on this by saying that "reading or learning is not recalled unless we have acted on it. The context of action then provides a focus for reading and learning”. (p23). In the complexity of our action research project we were acting upon our reading by implementing changes and evaluating their effect.

\section{Lessons to be learnt from this collaborative group}

John Heron (in Boud, Keogh and Walker, 1985) describes 'co-operative enquiry’ as primarily a way of doing research with people rather than on people. It breaks down the distinction between researcher and subject: the researchers are also co-subjects and the subjects are also co-researchers. (p128)

In a very real sense this is how our research group worked and we derived strength from this as "everyone involved move[d] between both roles.” (ibid) We were 'researchers' 
in terms of instigating the interviews, but 'researched' in that we were the subjects of those interviews.

The involvement of all participants, as equal members of the group, was essential to the success of our group. In the same way as the best gardens are the result of co-operation between people with different ideas and skills (for example Vita Sackville West / Harold Nicholson at Sissinghurst and Gertrude Jekell / Edwin Lutyens in over 120 gardens they designed in the early part of the $20^{\text {th }}$ century) we each contributed our ideas and skills to develop our understanding of action research and improve our practice in supervising dissertation students. Were we just lucky to have found a group of people who could work together in this collaborative and co-operative way, (in the way Vita and Harold and Gertrude and Edwin found each other) or are there lessons to be learnt from our project for others? If so the following are the three features of the context which made it possible, for me, to learn in the way I did, and may prove useful for others contemplating engaging in collaborative action research.

\section{(i) Lack of hierarchical barriers to open and honest discussion}

In our working context there are fewer hierarchical relationships than there might be in other organisations where rank or some other position or title might mean that some members of the group are regarded as more senior and therefore are automatically the 'leader'. It may be necessary for those involved in this type of co-operative enquiry to agree in advance that their research group will not recognise the titles or rank which pertain elsewhere in the organisational structure. Richard Winter argues that for true 
collaboration it is necessary to "suspend the conventional status hierarchy which gives some members’ viewpoints greater credibility than others” (Winter in Zuber-Skerritt, 1996, p22). This of course may not be possible in some organisations and could make working in this way very difficult or impossible.

(ii) A supportive leader / facilitator whose purpose was not to impose his/her own ideas on the project.

It could be seen as paradoxical that individuals in a collaborative group are equal partners but still there is a leader. How can you have a leader if everyone is equal? This rests in the quality of the 'leader', who, in the case of our action research project, is more accurately described as a facilitator. Our project had the benefit of having a facilitator who was supportive, not directive and gave time and energy to 'holding it together' when everyone was hard pressed.

Burchell (2000) has discussed the facilitator's role, albeit in a different context to our project, in terms of how far the facilitator should 'direct' the group or let it make its own decisions. She explores how, acting as a "facilitator ... as critical friend” (p226), the group began to see the value of action research. The role described here is similar to that of the role of our facilitator who was not judgmental and encouraged each individual to contribute what she could.

(iii) No need for a 'quick fix' solution to some 'problem' 
Research is often seen as a way to get a quick fix to a problem, whether this is at a local or national level. This could lead to two possible difficulties which were not present in our research project:

a) imposed group membership might bring resentment and an unwillingness to cooperate;

As has been noted previously this was a self-selecting group. Five supervisors, from a much larger potential number who supervised dissertation students, engaged in the project voluntarily. As early as 1977 Lomax (Lomax \& Whitehead, 1998) argued "that teachers should identify their own professional development needs rather than have them determined by ...management” (p448). The fact that we came together voluntarily to work on aspects of our practice may have contributed to the success of our collaborative project. There was no 'problem’ to be solved - we had a genuine interest in improving our individual practice but without there being any suggestion that we would impose what we found on others. We would share what we discovered for ourselves with those in the action research group, but we recognised that as individuals we all have individual styles of supervision, so each would need to make sense of the outcomes from her own perspective.

b) a time limit on outcomes could place additional pressure on participants.

The experience of being involved in this project has highlighted the need to recognise that reflection to enable professional learning to take place needs time and cannot always be achieved in an imposed time scale. Time is needed not only for reading, discussion and writing but, more importantly, for engaging with others, giving support to and 
receiving support from them. Susan Knight (in Boud, Keogh and Walker, 1985) argues that "in the learning situation, reflection is most profound when done aloud with the aware attention of another person” (p85). She is writing about her experience in a cocounselling one-to-one reflective relationship but a parallel can be drawn between this and collaborative action research of the kind we were involved in.

In our project there were times when there was little overt 'activity', although, for me the reflection and thinking continued. Action research, like the garden, needs these 'fallow' periods when, although it appears nothing is happening, the soil is recovering for another burst of activity. A garden does not look good all year round and, like action research, has its highs and lows. If results are needed in a short time scale there would be no large shrubs and trees, just annual plants which wither and die when the first frost hits.

\section{Conclusion}

I began this chapter by saying that I'd rather be gardening. However, engagement in the learning process is also absorbing. You never stop learning about both gardening and action research. There are some interesting similarities to be drawn between the experiences. I have learnt about gardening through a combination of:

- $\quad$ reading about it

- visiting other gardens and having people visit mine

- discussing and debating with other gardeners (with similar or different views)

- $\quad$ putting ideas into practice

- $\quad$ experimenting to see what works where (including making mistakes) 
All these activities lead to a greater understanding of my own garden and general principles, and have helped me establish my own view or philosophy of gardening. This involves ensuring the soil is well nourished and the plants are healthy, so that various aspects of nature have an opportunity to work in harmony to establish a balance and grow in places where the conditions are right.

There are similarities between this process and the way in which professional development can take place through involvement in a collaborative action research project. My own learning took place through:

- $\quad$ reading about it

- observing others' tutorials and having mine observed by others

- discussing and debating with other supervisors (with similar or different views)

- putting ideas into practice

- experimenting to see what works

My involvement in the Action Research Group has certainly provided me with the continued motivation to question and develop my own practice. It has also enabled me to gain greater knowledge and understanding about many aspects of the supervision process. It enabled me to start to develop a 'philosophy' of supervision in which I attempt to ensure the student's ground work (soil) is well established and their ideas (plants) are well nourished. I have also begun to implement a better balance between my input and the students' ideas, opinions and experience to enable them to develop in the way that 
most suits their conditions. It also provided a framework which enabled me to make time for thinking and reflecting and gain the particular kind of support I needed to learn from reading what others had written about action research. I would not have done this had I not been part of the group - for me “you can’t do it on your own” has become an essential realisation. 